\title{
Alteration of the phenology of leaf senescence and fall in winter deciduous species by climate change: effects on nutrient proficiency
}

\author{
M. Estiarte ${ }^{1,2}$ and J. Peñuelas ${ }^{1,2}$ \\ ${ }^{1}$ CSIC, Global Ecology Unit CREAF-CSIC-UAB, Cerdanyola del Vallès 08193, Barcelona, \\ Catalonia, Spain, \\ ${ }^{2}$ CREAF, Cerdanyola del Vallès 08193, Barcelona, Catalonia, Spain
}

\begin{abstract}
Leaf senescence in winter deciduous species signals the transition from the active to the dormant stage.

The purpose of leaf senescence is the recovery of nutrients before the leaves fall. Photoperiod and temperature are the main cues controlling leaf senescence in winter deciduous species, with water stress imposing an additional influence. Photoperiod exerts a strict control on leaf senescence at latitudes where winters are severe and temperature gains importance in the regulation as winters become less severe. On average, climatic warming will delay and drought will advance leaf senescence, but at varying degrees depending on the species. Warming and drought thus have opposite effects on the phenology of leaf senescence, and the impact of climate change will therefore depend on the relative importance of each factor in specific regions. Warming is not expected to have a strong impact on nutrient proficiency although a slower speed of leaf senescence induced by warming could facilitate a more efficient nutrient resorption. Nutrient resorption is less efficient when the leaves senesce prematurely as a consequence of water stress. The overall effects of climate change on nutrient resorption will depend on the contrasting effects of warming and drought. Changes in nutrient resorption and proficiency will impact production in the following year, at least in early spring, because the construction of new foliage relies almost exclusively on nutrients resorbed from foliage during the preceding leaf fall. Changes in the phenology of leaf senescence will thus impact carbon uptake, but also ecosystem nutrient cycling, especially if the changes are consequence of water stress.
\end{abstract}


Keywords: climate change, drought, leaf senescence, leaf fall, litter, phenology, nutrient cycle, nutrient proficiency, plant production, warming, winter deciduous species.

Running title: Leaf-fall phenology and nutrient proficiency 
Climates outside the equatorial belt alternate between seasons having conditions favorable for biological activity and seasons having limiting conditions. Perennial plants have adapted their life cycles to this seasonality, developing an activity-dormancy cycle that alternates an active period for growth and photosynthesis with a dormant period for survival through unfavorable conditions. Woody plants in temperate and boreal ecosystems, having winter as the unfavorable season, manage their foliage differently during dormancy: evergreen species maintain their leaves whereas deciduous species shed all foliage.

The transitions between active and dormant stages are easily recognizable in deciduous species because of greening during budburst and because of leaf yellowing or coloring and leaf fall. Leaf senescence is the last stage in the lives of leaves and is visually identified by a change in the color of leaves from green to yellow or red. The date of leaf coloring is used to quantify the phenology of leaf senescence; leaf senescence and change in color are commonly synonymous in the literature and in this article. When quantification of date is not the issue, leaf senescence can also refer to the entire process. The process of leaf senescence includes several physiological changes that will be described later. We use "process of leaf senescence" and "to progress" when referring to the dynamic aspects of leaf senescence. Leaf fall is the next step after leaf senescence and in most cases is tightly related to it to such an extent that it can be used as a proxy of leaf senescence, assuming a certain delay in time.

\section{Alteration of phenology in winter deciduous species by climate change}

The conspicuous events of greening and coloring of the foliage have facilitated the collection of longterm phenological records that, together with satellite records, have allowed the study of trends in plant and vegetation phenology. Evidence is accumulating that the timing of the transitions between active and dormant stages has been changing, and the changes are assumed to be a consequence of climate change. Phenological records indicate that leaf unfolding has advanced an average of 2-3 days per decade for the last five decades (Peñuelas \& Filella, 2001, Peñuelas et al., 2002, Menzel et al., 2006, Gordo \& Sanz, 2009) and that leaf senescence or fall has been delayed by 1-2.5 days per decade (Menzel \& Fabian 1999; Peñuelas et al., 2002; Matsumoto et al., 2003; Gordo \& Sanz, 2009). Changes 
in the dates of leaf senescence and fall in the phenological records, however, are slower, more heterogeneous and less consistent than those for leaf unfolding (Peñuelas et al., 2002; Gordo \& Sanz, 2009; Menzel et al., 2006).

Spring and autumnal phenologies impact forest productivity because they define the length of the growing season. Longer growing seasons are a consequence of advanced budburst or/and delayed leaf senescence. The analyses of 20-25 years of satellite observations from the 1980 s to the 2000 s have shown that the start of the growing season has advanced by 5.4 days, and the end of the growing season has been delayed by 6.6 days in the temperate vegetation of the Northern Hemisphere (Jeong et al., 2011), and that the end of the growing season has been delayed by an average of $0.4 \mathrm{~d} \mathrm{y}^{-1}$ in the deciduous forests of eastern USA (Dragoni \& Rahman, 2012) and by $0.42 \mathrm{~d} \mathrm{y}^{-1}$ in Europe (Stöckli \& Vidale, 2004). The longer the period with green foliage, the larger the $\mathrm{C}$ uptake and productivity of forests. For example, in a 10-year record of net ecosystemic exchange in a deciduous forest, a delay of $3 \mathrm{~d} \mathrm{y}^{-1}$ in leaf senescence paralleled an increase in net ecosystemic productivity of $5 \mathrm{~g} \mathrm{C} \mathrm{m}^{-2} \mathrm{y}^{-1}$ in late summer (Dragoni et al., 2011).

Ecosystemic productivity is key for the functioning of the Earth system, as demonstrated by the coordination of alternating climatic seasons with the annual dynamics of increases and decreases in atmospheric $\mathrm{CO}_{2}$ levels (Keeling et al., 1996). Efforts to disentangle the effects of climate change on the phenology of the vegetation have been mostly motivated by the implications of productivity on the $\mathrm{C}$ cycle and, hence, on global climate. Modeling predicts advances in leaf appearance of 5-9 days during this century (Morin et al., 2009). The modeling of leaf senescence in winter deciduous species is less satisfactory, and the results are good for some species but not for others (Vitasse et al., 2010). Models predict a delay of circa 1.5-2.5 days per decade in the current century (Delpierre et al., 2009; Lebourgeois et al., 2010; Dragoni et al., 2011; Archetti et al., 2013), although no changes are predicted for some individual species (Archetti et al., 2013).

At the individual level, longer seasons improve competitive ability if $\mathrm{C}$ uptake is not compromised by the potential damage of frosts. Advancing leaf unfolding increases the risk of latespring frosts that could kill new tissues and further affect production. Delaying leaf senescence 
increases the risk of early-autumnal frosts that could kill leaves before the completion of nutrient resorption during senescence and could reduce the nutrient reserves that support growth in the next season (e.g. Frachenoud et al., 2009, Schreiber et al., 2013). Indeed, the main function of the process of leaf senescence is the recovery of nutrients before leaves detach from the perennial organs of the plant.

\section{Aspects of the physiology of leaf senescence and of leaf biochemistry relevant to nutrient resorption}

Leaf senescence consists of the orderly degradation of the cells of the leaf, leading to cell death and ultimately to leaf fall. The degradation of the cells is a prerequisite step required for the resorption of nutrients. Nutrient resorption is not absolute, and falling leaves retain a certain amount of nutrients, whose concentrations represent the proficiency of nutrient resorption (Killingbeck, 1996). The proportion of the nutrients in green leaves prior to senescence that are resorbed before abscission is known as the nutrient-resorption efficiency (Aerts, 1996; Killingbeck, 1996).

Senescence implies a radical change in foliar metabolism that shifts from assimilation to the remobilization of resources, as shown by the dynamics of the transcriptomes, proteomes, and metabolomes of foliar cells. The onset of leaf senescence, the tipping point in the transition from anabolism to catabolism, manifests before the mentioned external signals are visible. The onset begins with the down-regulation of genes associated with photosynthesis and with the up-regulation of genes associated with senescence (Breeze et al., 2011; Guo, 2013).

By the end of the process of leaf senescence, a large fraction of the mobile nutrients have been transferred to the perennating organs. The recovery of nutrients is a complex challenge given the variety of nutrient-containing molecules and the compartmentalization in organelles. Leaf senescence proceeds sequentially beginning with the disassembly of the chloroplast, while mitochondria and nuclei remain functional (Inada et al., 1998; Keech et al., 2007). The degradation of chlorophyll, the cause of the characteristic leaf yellowing, occurs early to prevent the formation of oxygen radicals that could disturb the activity of enzymes (Hortensteiner, 2006). Mitochondria maintain integrity until the 
last stages of senescence, with respiration supplying the ATP and C skeletons needed for nutrient resorption (Keech et al., 2007).

The main nutrients withdrawn from senescent leaves are N, P, K, and S, the macronutrients that are mobile in the phloem, whereas $\mathrm{Ca}$ and $\mathrm{Mg}$, the other two macronutrients, are less mobile and are often accreted rather than resorbed at the end of the process (Vergutz et al., 2012; see review in Killingbeck, 2004).

Proteins are abundant N-containing macromolecules. Chloroplasts contain $50-60 \%$ of the $\mathrm{N}$ in leaves (Mostowska, 2005), half of which is in Rubisco. Nucleic acids contain 10-15\% of the foliar $\mathrm{N}$ (Chapin \& Kedrowski, 1983; Evans \& Seemann, 1989), and minor amounts are found in cytosolic proteins, chlorophyll, and amino acids (Fischer, 2007). Up to $9 \%$ of the foliar $\mathrm{N}$ is in proteins attached to cell walls (Onoda et al., 2004). S is found in the amino acids cysteine and methionine and therefore has the same distribution as $\mathrm{N}$ in proteins.

Most plant $\mathrm{P}$, circa 58\%, is in inorganic forms, and the remainder is distributed among RNA (18\%), lipids (13\%), and esters (9\%), with only $2 \%$ found in DNA (Sanchez, 2006). The proportion of $\mathrm{P}$ in RNA has notably sometimes been overestimated because of its importance in protein synthesis (see Matzek \& Vitousek, 2009). K does not occur in macromolecules but is found as soluble ions. $\mathrm{K}$ is thus highly mobile and can potentially be leached, which accounts for the uncertainties in the exact proportion of $\mathrm{K}$ actually resorbed.

Nutrient-containing macromolecules are degraded and transformed into molecules suitable for transport from the leaf. A plethora of hydrolases (proteases, ribonucleases, and lipases) is required for the degradation of the wide variety of macromolecules (for a review see Mostowska, 2005). Enzymes involved in $\mathrm{N}$ metabolism are also required for the deamination of nucleotides and proteins to liberate free ammonia, which is needed for the synthesis of glutamine and asparagine. These two amino acids are preferred for $\mathrm{N}$ transport in the phloem, whereas $\mathrm{P}$ is transported mostly in inorganic form, although organic P compounds are also found in the phloem (Peng \& Li, 2005).

Nutrient-resorption efficiencies in woody deciduous plants were considered to average $54 \%$ for $\mathrm{N}$ and 50\% for P (Aerts, 1996), but more realistic values obtained after correction for the mass lost 
during the process raise the efficiencies to $62 \%$ for $\mathrm{N}, 65 \%$ for $\mathrm{P}$, and $70 \%$ for $\mathrm{K}$ (Vergutz et al., 2012). Resorption efficiencies for $\mathrm{N}$ may be as high as $90 \%$, as described for Populus tremula (Keskitalo et al., 2005).

Nutrient-resorption efficiency and nutrient proficiency, the nutrient concentration in falling leaves, are not constant across years (Killingbeck, 1996). For example, $\mathrm{N}$ concentrations in the falling leaves of Acer saccharum over a 15-year period ranged from 6.3 to $10.8 \mathrm{mg} \mathrm{N} \mathrm{g}^{-1} \mathrm{DW}$ in a natural forest and from 6.7 to $14.3 \mathrm{mg} \mathrm{N} \mathrm{g}^{-1} \mathrm{DW}$ in a forest with $\mathrm{N}$ deposition (Pregitzer et al., 2010) (Fig. 1). The minimum concentration that can be reached after resorption is the limit for potential resorption and indicates the maximum proficiency. Resorption in deciduous species is generally considered complete when $\mathrm{N}$ and $\mathrm{P}$ concentrations are below 0.7 and $0.05 \%$, respectively (Killingbeck, 1996). Incomplete resorption occurs when the degradation of macromolecules or the export of mobile compounds containing nutrients is not completed. Potential resorption depends on foliar characteristics and on the amounts of nutrients in macromolecules not suitable for degradation (Killingbeck \& Costigan, 1988; Killingbeck, 2004). Foliar N, for example, is found in pools associated with the metabolic machinery and with structural components (Charles-Edwards et al., 1987). The structural pool is considered unsuitable for resorption (Anten \& Werger, 1996; Hikosaka, 2003), at least the fractions embedded in cell walls (Yasumura et al., 2005).

\section{Significance of nutrient resorption for winter deciduous plants and ecosystems: the case of $\mathrm{N}$}

The nutrient content of green foliage represents a large fraction of the total nutrient content in plants. The resorption of nutrients implies important annual fluxes, e.g. $47 \mathrm{~kg} \mathrm{~N} \mathrm{ha}^{-1}$ (about $56 \%$ of the total $\mathrm{N}$ ) in a stand of Quercus serrata (Migita et al., 2007) or 7-27 $\mathrm{kg} \mathrm{N} \mathrm{ha}^{-1}, 0.5-1.8 \mathrm{~kg} \mathrm{P} \mathrm{ha}{ }^{-1}$, and 1.8- 5.3 $\mathrm{kg} \mathrm{K} \mathrm{ha}{ }^{-1}$ in several coppices of Q. pyrenaica (Gallardo et al., 1999). Changes in the flux of resorbed nutrients are accompanied by symmetrical changes in the flux of nutrients returned to the soil with the fallen leaves.

Perennial plants contain a pool of mobilizable $\mathrm{N}$ that in deciduous plants is alternatively located in leaves or woody tissues following the seasonal cycle (Fig. 2) and that in evergreens is mobilized 
from old to new leaves. During the dormant season, woody tissues of deciduous plants, but especially one-year-old twigs, store $\mathrm{N}$ mainly as storage proteins in the bark but also as amino acids. When the active season resumes, $\mathrm{N}$ flows toward newly formed tissues. Large amounts of $\mathrm{N}$ go to Rubisco in the leaves, a protein that, in addition to its key role in $\mathrm{C}$ fixation, has been considered to also have a storage function (Cooke \& Weih, 2005; Millard et al., 2007). When the active season ends, leaf senescence remobilizes a large proportion of the $\mathrm{N}$ back to the woody tissues. In Prunus persica, for example, at an N-resorption efficiency of 50\%, resorption from foliage could provide an estimated $80 \%$ of the $\mathrm{N}$ stored in overwintering organs (Niederholzer et al., 2001).

The internal cycling of $\mathrm{N}$ improves resource economy because it saves plants from devoting resources and energy to acquire new $\mathrm{N}$. The importance of internal cycling, however, is more strategic because it allows intense growth at the beginning of the season. The flush of new biomass in spring is supported, at least initially, almost exclusively by $\mathrm{N}$ already stored in the plant (Neilsen et al., 1997; Ueda et al., 2009; Pregitzer et al., 2010; Jordan et al., 2012). Stored N enables early spring growth independent of potentially unfavourable soil temperatures, although newly acquired $\mathrm{N}$ can later be supplemented for newer growth (Rennenberg et al., 2010). For example, remobilized $\mathrm{N}$ in $Q$. petraea contributes circa $90 \%$ of the total $\mathrm{N}$ in growing leaves and twigs in the first two weeks following budburst, but later newly absorbed $\mathrm{N}$ progressively increases, reaching $27 \%$ in fully expanded leaves and $18 \%$ in developed twigs (El Zein et al., 2011). Moreover, shoots of $A$. saccharum are constructed with $\mathrm{N}$ taken up in previous years, in contrast to fine roots that are constructed from newly absorbed $\mathrm{N}$ (Pregitzer et al., 2010). Enhancing C uptake in early season thus depends not only on early budburst, but also on the appropriate supply of nutrients for the formation and functioning of new leaves. Plants can optimize this early supply by adjusting the timing of leaf senescence to optimize nutrient resorption.

\section{Getting ready for overwintering}

Leaf senescence is one among many successive functional and structural changes that prepare plants adapted to climates with cold seasons for survival in winter. The preparations start long before the 
arrival of the unfavorable conditions. The first change is the cessation of growth in the middle of the active season in species with free growth for avoiding the presence of active tissues, which are inadequate for overwintering (e.g. Petterle et al. 2013). It is followed by bud set to protect meristems with bud scales. Concomitantly with these morphogenetic changes, biochemical changes occur at the cellular level, such as starch catabolism for supplying C skeletons for the synthesis of cryoprotectants (Keskitalo et al., 2005; Druart et al., 2007) or the accumulation of bark storage proteins (Clausen \& Apel, 1991; Resman et al., 2010). At this stage, plants have acquired endodormancy and do not respond to signals that promote growth (for details see Rohde \& Bhalerao, 2007; Campoy et al., 2011; Cooke et al., 2012). Leaf senescence occurs near the end of this succession of events leading to the dormant stage, but later cellular changes can still occur to further increase frost hardiness.

Plants adapt to climate with an optimal phenological calendar, maximizing competitive ability by adjusting the phenologies of leaf unfolding and senescence but also by maximizing winter survival by adjusting the phenology of the events that prepare plants for overwintering to avoid injures to the perennating organs. Populations at different latitudes differ in their response to environmental cues, most notably to photoperiod, suggesting selection pressure on autumnal phenology. Such differentiation has been described for phenological events such as growth cessation (Soolanayakanahally et al., 2013), bud set (Ingvarsson et al., 2006; Friedman et al., 2011; Soolanayakanahally et al., 2013), leaf senescence (Pudas et al., 2008; Fracheboud et al., 2009; Friedman et al., 2011; Soolanayakanahally et al., 2013), cold hardiness (Friedman et al., 2011), and dormancy (Ruuhola et al., 2011).

The predictability of photoperiodic dynamics makes day length a reliable signal for anticipating cold and frosts before they occur, whereas temperature is reliable for confirming the arrival of warmth. Budburst is not triggered until a sufficient accumulation of warm days, indicating that frosts have become unlikely and preventing responses to occasional warm spells that can be followed by frosts. Preparations for winter dormancy, though, are largely triggered by photoperiod: experimentally transferring plants to shorter days elicits growth cessation (Resman et al., 2010) and bud set 
(Ingvarsson et al., 2006), the up-regulation of genes for starch catabolim (Resman et al., 2010), and increase the transcription and accumulation of bark storage proteins (Wildhagen et al., 2013).

\section{Environmental controls of leaf senescence and fall and the effects of climate change}

Photoperiod versus temperature. Leaf senescence has been associated with other phenological events, as shown by intra- and inter-year correlations with growth cessation and cold hardiness in Populus (Friedman et al., 2011). Leaf senescence can thus be expected to also be under photoperiodic control to a certain degree, similarly to other events that prepare plants for overwintering. Accordingly, multiyear records for P. tremuloides (Barr et al., 2004) and P. tremula (Fracheboud et al., 2009), showing consistent leaf senescence dates, and experiments with P. balsamifera in which leaf senescence was not responsive to temperature (Soolanayakanahally et al., 2013), suggest a strong photoperiodic regulation of leaf senescence at latitudes with severe winters. Additionally, P. deltoides along a latitudinal gradient and growing in common gardens displayed a strong genetic component associated with latitudinal origin, associating variation in the phenology of leaf fall with photoperiod (Friedman et al., 2011).

Many reports show that the photoperiodic control of the phenology of preparation for overwintering can be modulated by temperature at varying intensities (see review by Tanino et al., 2010), and temperature can similarly modulate and even be the main control of leaf senescence (Fig. 3a). At lower latitudes where winters are less severe, temperature exerts a certain amount of control on autumnal phenology, likely allowing plants to benefit from additional $\mathrm{C}$ uptake in warm autumns. For example, warmer temperatures delay leaf senescence in populations of Betula pubescens in the south but not in the north of Finland, where photoperiodic control is not relaxed (Pudas et al., 2008). Thermal control has been demonstrated by delays in leaf senescence or fall for single species in a single year across altitudinal gradients with uniform photoperiods (Richardson et al., 2006; Vitasse et al., 2009, 2011; Cufar et al., 2012). At a particular location, where photoperiod dynamics remain unchanged across years, thermal control has been demonstrated by positive correlations between the timing of leaf senescence or fall and the temperatures in preceding periods of variable length (Peñuelas 
et al., 2002; Doi \& Takahashi, 2008; Gordo and Sanz, 2010; Ibañez et al., 2010; Lebourgeois et al., 2010; Matsumoto, 2010; Cufar et al., 2012; Archetti et al., 2013; ) and by models of accumulated colddegree days adjusted with data for leaf senescence (Richardson et al., 2006; Archetti et al., 2013). At a larger scale, an increasing influence of temperature on the leaf fall phenology of the deciduous forests at lower latitudes has been recently described across the latitudinal gradient in eastern USA where the responsiveness to accumulated cold-degree days at the end of the season is nearly three times higher at lower $\left(31^{\circ} \mathrm{N}\right)$ than at higher $\left(48^{\circ} \mathrm{N}\right)$ latitudes (Dragoni \& Rahman, 2012).

Many observational studies thus support the importance of temperature on the control of leaf senescence and subsequent leaf fall. A special case is represented by the Rosacea family, several of whose species respond strongly to temperature but not to photoperiod for growth cessation, bud set, dormancy, and leaf senescence (Heide \& Prestrud, 2005; Heide 2011). Malus domestica, for example, sheds its leaves nearly a month earlier in a cold than in a warm year (Wibbe et al., 1994). This null control by photoperiod of the events related to overwintering has been hypothesized to be a consequence of a deficiency in signal transduction rather than in photoperiodic sensitivity (Heide, 2011). How the control of leaf senescence is split between photoperiod and temperature, however, is not known for many important species.

A delay in leaf senescence and fall is the most common response in experiments of warming (Chung et al., 2013). The average leaf fall was delayed by 8 and 13 days with 2 and $4{ }^{\circ} \mathrm{C}$ warmer temperatures, respectively, in four species (Gunderson et al., 2012) and by averages of 7.5 and 13 days with a warming of $4{ }^{\circ} \mathrm{C}$ in two species of Acer (Norby et al., 2003). Similar delays have been reported for other species (Nakamura et al., 2010; Xu et al., 2012). Different results, however, have also been reported, such as a 15-day delay in leaf senescence with a warming of $1.5^{\circ} \mathrm{C}$ in one winter deciduous species of Quercus, but not in another (Morin et al., 2010). A lack of an effect of experimental warming on yellowing has also been described in three Arctic species of Salix subjected to warmer air and soil temperatures of $1-4{ }^{\circ} \mathrm{C}$ in open-top chambers (Jones et al., 1997).

The reported lack of changes in leaf senescence in an Artic warming experiment described by Jones et al. (1997) supports photoperiod as the main control where winters are severe. The absence of 
thermal controls on leaf senescence, however, is not restricted to high latitudes. In an altitudinal gradient in southern France, the lack of a correlation between the timing of leaf senescence and temperature in Fraxinus excelsior and A. pseudoplatanus, in contrast to the correlations found for Fagus sylvatica and Q. petraea (Vitasse et al., 2009), suggests that leaf senescence in the former species is controlled by photoperiod. Leaf fall was also not correlated with temperature in 5 of the 25 Mediterranean species monitored over a 50-year period in Catalonia (Peñuelas et al., 2002), but this observation could be due to the inter-year variability in water stress, which may also affect the timing of leaf senescence and can mask the effects of temperature.

Leaf senescence advanced by 20 days in seedlings of $F$. sylvatica and $Q$. robur subjected to 6 ${ }^{\circ} \mathrm{C}$ warmer temperatures during winter and before leaf flushing in early spring, which was attributed to a legacy of much earlier spring flushing in leaves of warmed saplings (Fu et al., 2014). The timing of leaf senescence was positively correlated with previous flushing dates in the long-term European phenological records of both species, indicating that even though recent environmental cues dominated the variability in the phenology of leaf senescence, they could not fully account for it, which led to the hypothesis that leaf senescence could be triggered by the sink limitation that indicates the accumulation of non-structural carbohydrates in the leaves. Some long-term records indicate a negative correlation between the dates of leaf senescence or leaf fall in the autumn and temperatures in May and June (Estrella \& Menzel, 2006; Gordo \& Sanz, 2010; Gunderson et al., 2012; Archetti et al., 2013), indicating that conditions experienced by the leaves long before leaf senescence may impact the timing of senescence. Efforts are needed to determine the relevance of this possibility for evaluating its inclusion in models and for discarding possible relationships with water stress.

Senescence in individual leaves has a marked onset and progresses until completed after the several steps that lead to nutrient resorption. Metabolism generally increases with temperature, but the few available data suggest that the progression of senescence in leaves is regulated by temperature, with slower, and thus longer, leaf senescence under warmer conditions. For example, higher temperature was assumed to slow senescence in the leaves of the upper crown exposed to the sun compared to the shaded leaves of the lower crown (Staaf \& Stjernquist, 1986), and colder temperatures 
may also account for the trend toward the faster progression of leaf senescence at higher latitudes (Doi \& Takahashi, 2008). Similarly, the time between leaf coloring and leaf fall was extended by two days in a 50-year record of Tilia cordata and Betula pendula (Juknys et al., 2012), suggesting that the duration of the process is affected by climatic warming. A lack of data prevents an evaluation of the importance of the speed of leaf senescence on the timing of leaf senescence, and whether the speed will or not be involved in a slight advancement of leaf senescence and fall (grey line in Fig. 3a). Accumulated evidence supports the projection that climatic warming will delay the onset of leaf senescence and fall (orange line in Fig. 3a) in many regions and species, but this projection can not be generalized. The magnitude of the delay will depend on the degree of photoperiodic control for particular species, with members of the Rosacea family experiencing the largest effect, and species and populations suffering severe winter conditions being unresponsive to the warming. The contributions of photoperiod and temperature to the control of leaf senescence need to be resolved to meet the challenges of projecting the direct effects of warming on the phenology of leaf senescence, but also for projecting the indirect effects in plants coping with altered photoperiods under the likely changes in species distribution induced by climate change. The delay in leaf fall expected toward the end of the century may have a component related to a slower leaf senescence under warmer temperatures, a component that may also be present in species whose onset of leaf senescence is under strict photoperiodic control.

Water stress and premature leaf senescence. The importance of water stress in leaf senescence is evident in drought-deciduous species of tropical dry forests (Murphy \& Lugo, 1986), and water stress is also important for other leaf habits and biomes. Earlier leaf fall in Mediterranean ecosystems is correlated with the onset of water deficit, both in evergreens and winter deciduous plants (Escudero \& del Arco, 1987). Evergreens have higher annual litter falls in years of summer drought (Pedersen \& Bille-Hansen, 1999) or have advanced leaf senescence and fall. For example, stands of Pinus tadea have an earlier peak of needle fall in dry years (Hennessey et al., 1992; Dougherty et al., 1995). 
Environmental stresses may cause leaves of winter deciduous plants to prematurely senesce before autumn in what is considered accelerated cellular senescence, in contrast to autumnal ontogenic senescence (Günthardt-Goerg \& Vollenweider, 2007). Ontogenic senescence and accelerated cellular senescence may be differentiated microscopically (Günthardt-Goerg \& Vollenweider, 2007), although they share many common steps. A large proportion of genes associated with senescence that are upregulated during ontogenic senescence (see Breeze et al., 2011) are also found in gene-expression profiles in response to hormone and stress treatments (Chen et al., 2002; Guo 2013). Oxidative stress, though, is more associated to accelerated cellular senescence than to ontogenic senescence (GünthardtGoergbut \& Vollenweider, 2007; Juvany et al., 2013), and the accumulation of reactive oxygen species is known to be a regulator of the process of leaf senescence (Munné-Bosch \& Alegre, 2004).

Leaf loss is considered a mechanism for the avoidance of water stress in plant species adapted to drought, because it reduces the transpiring surface of the foliage and therefore reduces the water demand and the risks of xylem embolism and plant desiccation. Leaves of deciduous species not adapted to drought may desiccate under intense water stress without undergoing senescence and hence without resorbing nutrients (Marchin et al., 2010). For example, F. sylvatica intensely and prematurely shed non-senesced green leaves during the dry and warm summer of 2003, the only episode reported during a period of 30 years (Breda et al., 2006).

Many species may present two peaks of leaf fall, a low peak in summer and the main peak in autumn (red line in Fig 3b), as described for two Populus species in forest patches on a Mediterranean floodplain (Gonzalez, 2012), for a Liquidambar plantation (Waren et al., 2011), and for saplings of $B$. pendula (Wendler \& Millard, 1996). Species whose prematurely fallen leaves resorbed nutrients before falling are better adapted to drought. A fraction of the foliage in these species prematurely undergoes senescence during water stress, usually in summer, but once the soil water recovers, the remaining foliage senesces later, during autumnal ontogenic leaf senescence at the end of the active season. Examples of this pattern are included in the next section.

Instead of early peaks, the effects of drought stress may also appear at the end of the cycle with an advance in seasonal leaf senescence. Logically, such an advance occurs in drought-deciduous plants 
in tropical dry climates (Walter, 1971 as cited in Murphy \& Lugo, 1986) and is easily explained by the advance of the unfavorable dry season. In temperate climates, however, drought in summer does not overlap with the cold season that triggers autumnal leaf senescence, but the effects of water stress may nonetheless be delayed by advances in leaf senescence at the end of the season that cannot easily be differentiated from ontogenic leaf senescence. Detailed observations are needed to determine whether the effects of drought promote a premature fall of the leaves more affected by drought, analogous to the early peak in summer, but delayed in time (blue line in Fig. 3b), with the unaffected leaves falling in autumn as though the drought had not occurred, or whether drought promotes a comprehensive shift in the dynamics of leaf fall toward early dates for all foliage, i.e. a general advance in the onset of senescence for all foliage (green line in Fig. 3b). Whichever is the case, several observations support an advance in senescence and fall of foliage due to drought and water stress, for example by positive correlations between the dates of leaf fall and precipitation in summer (Gordo \& Sanz, 2010), by the negative relationship between summer rainfall and the percentage of senescent leaves in mid-October in one Quercus species (Montserrat-Martí et al., 2009), and by similar results for other Quercus species under experimental drought (Silla \& Escudero, 2004; Günthardt-Goerg et al., 2011). Accordingly, the inconsistent trends in leaf fall across an altitudinal gradient in a montane watershed were due to an earlier leaf senescence under drier late seasons at low elevation that arose from the negative correlations with precipitation from July to October, with a sensitivity of an advance of 0.56 days per 100-mm decrease in rain (Hwang et al., 2014).

More focused studies are needed to complete our understanding of the different effects of drought stress on leaf senescence and fall, especially for the autumnal fall, but also to determine if the more gradual leaf fall of drought-adapted species under field conditions (del Arco et al., 1991) is regulated by external factors, i.e. drought induces either a premature summer peak (red line in Fig. 3b) or an earlier leaf senescence in autumn in the more damaged leaves (blue line in Fig. 3b), or if gradualness is a constitutive trait in drought-adapted species and can also partially manifest under conditions of no water stress. 
Long-term records fail to show a clear relationship between precipitation and leaf senescence and fall. Estrella \& Menzel (2006) found no overall correlations between the timing of leaf senescence and monthly precipitation. Precipitation also had no clear effect on the timing of leaf fall in the Mediterranean region, which is prone to drought (Peñuelas et al., 2002; Gordo \& Sanz, 2010). Some weak correlations between leaf fall and monthly precipitation have been proposed by more elaborate modeling (Archetti et al., 2013). Partial support is provided by the positive, but very weak, relationship between the end of season estimated from satellite observations and precipitation from May to September in deciduous forests in the USA, but only within an interval of the latitudinal gradient studied (Dragoni \& Rahman, 2012).

The opposite effects of warming and water stress on the phenology of leaf senescence may contribute to the unclear relationship between previous temperatures and the timing of leaf senescence. Advanced, instead of delayed, leaf fall in B. pendula over a 50-year period was attributed to a decrease in soil moisture caused by a simultaneous rise in temperature and decrease in precipitation (Juknys et al., 2012). Similarly, the dates for offset of season usually tracked August and September temperatures in a 16-year period in deciduous forests, except when late summer drought caused premature leaf senescence (Gunderson et al., 2012). Accordingly, the interference of water stress prevented the patterns of leaf senescence from following the temperature gradient across an altitudinal gradient (Hwang et al., 2014). Interaction between warming and water stress may also explain the 22-day delay of leaf fall observed after an unusually low precipitation combined with a warm summer in 2003 in a mixed deciduous forest (Leuzinger et al., 2005).

The projected increase in the number and intensity of droughts in many regions (IPCC, 2013) can potentially advance leaf senescence and fall due to either premature summer peaks caused by a more gradual leaf fall or simply due to earlier autumnal peaks. Whenever drought and warming coincide, the advancing effects of drought will counteract the delaying effects of the warming of the climate. Thereafter, the final effect at the end of the active season on the phenology of leaf fall will depend on the balance between the effects of warming and those of drought. In regions where water stress is likely to increase, either because of changes in precipitation or because of higher evaporative 
demand due to warming, the phenologies of leaf senescence that can currently be projected are probably inaccurate, not only because the effect of drought on the phenology of many species is poorly known, but also because of the lack of observations on the interaction with temperature.

\section{Effects of climate change on nutrient concentrations of falling leaves}

Killingbeck (2004) identified several determinants of realized resorption including i) plant physiological status that depends on fertilization or radiation, i.e. available energy, nutrient concentration, or enzymatic activity; ii) existence of a sink demand for nutrients; iii) disturbances; iv) water stress during leaf senescence; and v) the timing of leaf senescence. Climate change may affect the proficiency of falling leaves through the direct impact of warmer temperatures and water stress on the phenology of leaf senescence and also on the other determinants of proficiency listed above.

The timing or phenology of leaf fall, which reflects mostly that of leaf senescence, is considered a cause of altered nutrient resorption (Killingbeck, 2004), assuming that timing itself is the cause of incomplete resorption without considering why or how the mechanisms controlling the degradation and mobilization of macromolecules are affected by the timing. Lower proficiencies of resorption with early leaf senescence or fall have been found between species (del Arco et al., 1991; Milla et al., 2005), between leaves of individuals and between years differing in precipitation (Killingbeck et al., 1990) and in the progression of leaf fall within stands (Niinemets \& Tamm, 2005). The effect of timing is supported by the chemical dynamics of falling leaves across the progression of leaf fall at the stand level in seven winter deciduous species (Niinements \& Tamm, 2005). In this study, leaves that fell early contained more nutrients, and the nutrient concentrations decreased linearly with time to match the lower concentrations in the leaves that fell later. Similar results have been reported for B. pendula in a mixed forest (Staelens et al., 2011) and in a stand of F. sylvatica (Pedersen $\&$ Bille-Hansen, 1999). The progressive reduction in mobile nutrients in fallen leaves as leaf fall progresses within a stand suggests that an intraspecific delay in the onset of leaf senescence induced by climate change will cause an increase in nutrient resorption. Other than the above observations, however, we have no evidence that a shift in the onset of leaf senescence (i.e. the up-regulation of 
genes associated with senescence and the down-regulation of genes associated with photosynthesis) affects the physiology and biochemistry of cells and leaves during senescence in a way that may alter the degree of nutrient resorption. The progressive increase in resorption as leaf senescence is delayed may have other causes. For example, leaves tend to fall earlier when affected by various stresses, such as water stress (Killingbeck, 2004), biotic stress (Waddell et al., 2001), or ozone stress (Kasurinen et al., 2012), and leaves are less proficient at resorption under water stress (Killingbeck, 2004) and herbivory (Silla et al., 2008), which may be the case for leaves falling early within a stand. We are of the opinion that nutrient resorption is not inherently determined by the date of leaf senescence and that the appropriate approach is to ascertain if the factor altering the phenology of leaf senescence affects any physiological step of the process of leaf senescence that regulates the resorption of nutrients.

These considerations need to be addressed before the effects of climate change on nutrient proficiency can be determined.

Warming. The effects of warming on nutrient proficiency will depend on whether leaf senescence is under strict photoperiodic control or is modulated by temperature. Species under strict photoperiodic control will not have an altered onset of leaf senescence but would likely have a slower speed rate of leaf senescence. The complex process of leaf senescence involves a coordinated sequence of steps that requires a certain amount of time to progress. For example, the complete resorption of $\mathrm{N}$ in $P$. tremula requires two weeks (Fracheboud et al., 2009). The mechanism of programmed cell death is much slower for leaf senescence than for other causes such as defense, indicating that time is required to complete the resorption of nutrients, (Lim et al., 2003). We hypothesize that a longer, i.e. slower, leaf senescence can allow a more thorough scouring of nutrients, so the realized resorption can approach the potential resorption. A longer duration of senescence may account, for example, for the higher efficiency of $\mathrm{N}$ resorption in leaves of the upper crown of $F$. sylvatica, in consonance with the slower senescence in the upper compared to the lower crown, and for the difference in efficiencies that was attributed to differences in temperatures (Staaf \& Stjernquist, 1986). 
A higher resorption of nutrients with longer senescence may also account for the higher nutrient proficiency of leaves falling later within a stand, given that late-falling leaves have likely senesced slowly and have had more time to achieve the most complete resorption from all foliage. This and the other arguments provided above suggest that the timing of leaf senescence is unlikely to be a determinant of nutrient resorption by itself but, should our reasoning be wrong, would imply that climatic warming would improve nutrient resorption in species with thermally modulated senescence, provided that resorption was not already maximal. As far as we know, however, the correct scenario has not been determined.

Species whose leaf senescence will be delayed by warming will confront higher risks of occasional reductions in nutrient proficiency, because warming increases the risk that early frosts will kill the leaves before they complete, or even begin, senescence (Norby et al., 2003; Gunderson et al., 2012). This possibility was experimentally supported in warmed Acer saplings whose leaves were killed by frosts and had higher $\mathrm{N}$ concentrations after falling than the leaves falling from saplings in the control, whose leaves were almost completely abscised and had completed resorption when the frosts occurred (Norby et al., 2003).

Drought. The premature leaf senescence caused by water stress is associated with a reduction in nutrient resorption (Killingbeck, 2004). Milla et al. (2005) recognized some physiological traits associated with drought that may potentially affect nutrient resorption: accumulation of proline and other amino acids (Feller \& Fischer, 1994), reduction in phloem loading due to the production of abscisic acid (Pugnaire \& Chapin, 1992), or possible disruption in the flow of water caused by xylem cavitation (Silla \& Escudero, 2004).

The effects of water stress are microscopically visible at the subcellular level (GünthardtGoergbut \& Vollenweider, 2007). Reports include increased thickness of the cell walls of the upper epidermis and pectinaceous projections in the cell walls of the mesophyll (Paakkonen et al., 1998) but also whorls in membranes, condensation of chromatin in the nuclear matrix and the nucleolus, swelling of chloroplasts, accumulation of plastoglobuli in the stroma, and apparent changes in the membrane 
system (Munné-Bosch et al., 2001). Alterations of cellular structures induced by water stress may impede the activity of catabolic enzymes and may account for the differences among nutrients in the effects of drought on resorption, depending on the cellular structure where the nutrient-containing macromolecules are located.

Species whose leaves are sensitive to intense water stress but do not undergo senescence shed all their nutrients when their leaves desiccate. A clear example was described during a drought in a mixed hardwood forest where $\mathrm{N}$ and $\mathrm{P}$ concentrations in fourteen species were the same in leaves that desiccated during the drought as in leaves that remained healthy, whereas leaves falling in the autumn after ontogenic senescence resorbed $35 \%$ of the $\mathrm{N}$ and $42 \%$ of the $\mathrm{P}$ (Marchin et al., 2010). In the same forest, the four species whose leaves underwent drought senescence resorbed nutrients from leaves falling in summer (50 and $12 \%$ for $\mathrm{N}$ and $\mathrm{K}$, respectively) less efficiently than from leaves falling in autumn (64 and 51\% for $\mathrm{N}$ and $\mathrm{K}$, respectively), whereas $\mathrm{P}$ was resorbed equally (50\%) in both seasons. Similarly, N concentrations in seedlings of $Q$. pyrenaica were $25 \%$ higher in droughtsenesced leaves falling in summer than in leaves falling in autumn (Silla \& Escudero, 2006), and the same pattern was found in a Liquidambar plantation (Warren et al., 2011) and in seedlings of $Q$. faginea (Silla \& Escudero, 2004).

Drought increases the gradualness of leaf fall and reduces $\mathrm{N}$ resorption in drought-adapted species in semiarid climates, as described by del Arco et al. (1991), but this report did not say if the effects on resorption were constant throughout the period of leaf fall or if they were due to a combination of leaves falling early being less proficient than leaves falling late because the first had been more affected by drought. The second option was reported for a Mediterranean winter deciduous shrub with a very gradual leaf fall from summer to autumn, whose summer-senesced leaves were less proficient for $\mathrm{N}$ and $\mathrm{P}$ resorption than autumn-senesced leaves (Milla et al., 2005).

Reports of the effects of drought on nutrient proficiency usually compare leaves that fall prematurely $v s$. those that fall in the autumn, or, when comparing treatments, use composite samples of both types of leaves. We are not aware of reports excluding prematurely fallen leaves and comparing only the ontogenically autumnal fallen leaves both in control and drought-stressed plants, but we find 
that, as far as drought affects cellular structures, nutrient resorption will likely also be lower under drought even when leaf senescence proceeds ontogenically. We do have, however, clear evidence that nutrient proficiency is reduced when the phenology of leaf senescence is altered by drought and leaves senesce prematurely. Current knowledge suggests, therefore, that the share of nutrients lost to the litter compartment will increase in regions where drought will be increased by climate change.

\section{Concluding remarks}

Climatic warming will most likely delay leaf senescence and fall in the many species sensitive to temperature but will have a weak, if any, effect in non-sensitive species or in populations adapted to high latitudes. The importance of drought on the control of the phenology of leaf senescence will be intensified whenever droughts become more intense and frequent either due to lower precipitation or to increasing water demands caused by warmer temperatures. The effects of advances of leaf senescence will depend on the intensity of the drought.

Advances or delays in leaf senescence and decreases or increases in the proficiency of nutrient resorption will depend on the species and on the site-specific counteracting effects of warmer temperatures and drought. Whenever the effects of warming dominate, leaf senescence will be delayed, and proficiency could slightly increase because of a slower speed of leaf senescence, but only if the potential resorption is not reached and in the absence of frosts that could disrupt leaf senescence. Whenever the effects of drought dominate, advanced leaf senescence and lower proficiency will occur in drought-senescent species as a function of the intensity of the drought. Under intense droughts, species not adapted to drought and unable to senesce in response to water stress will lose all the nutrients in desiccated leaves, whereas drought-adapted species will resorb nutrients from droughtsenesced leaves, although in lower amounts than in ontogenically senesced leaves. The contrast between the effects of warming and those of drought and the interspecific variability of the controls exerted by photoperiod hinder the projection of the effects of climate change on the timing and chemistry of leaf fall. 
The effects of climate change on the phenology of leaf senescence may directly and indirectly affect plant economy. Direct effects will be through alterations in the length of the growing season that will modify $\mathrm{C}$ uptake. Indirect effects will result from alterations in nutrient resorption that modify the nutrient pool available for growth at the beginning of the new active period. The size of the pool of mobile nutrients affects the $\mathrm{C}$ economy of the next cycle due to the cost of de novo acquisition of nutrients from the soil to replace the unresorbed nutrients lost with leaf fall and because the capacity for $\mathrm{C}$ uptake in early spring, and perhaps beyond, depends on the allocation of nutrients to new tissues from the mobile pool stored in wood in winter. Beyond the plant functioning, alterations of the nutrient resorption from leaves will symmetrically alter the nutrient flow towards the soil mediated by the mostly synchronized falling of leaves of deciduous species.

\section{Acknowledgements}

This work was supported by the Spanish Government grants CGL2013-48074-P and Consolider Ingenio MONTES CSD2008-00040, the Catalan Government grant SGR2014- 274, and the European Research Council Synergy grant ERC-SyG-610028 IMBALANCE-P.

\section{References}

Aerts R (1996) Nutrient resorption from senescing leaves of perennials: are there general patterns? Journal of Ecology, 84, 597-608.

Anten NPR, Werger MJA (1996) Canopy structure and nitrogen distribution in dominant and subordinate plants in a dense stand of Amaranthus dubius L with a size hierarchy of individuals. Oecologia, 105, 30-37.

Archetti M, Richardson AD, O'Keefe J, Delpierre N (2013) Predicting climate change impacts on the amount and duration of autumn colours in a new england forest. Plos One, 8.

Barr AG, Black TA, Hogg EH, Kljun N, Morgenstern K, Nesic Z (2004) Inter-annual variability in the leaf area index of a boreal aspen-hazelnut forest in relation to net ecosystem production. Agricultural and Forest Meteorology, 126, 237-255.

Breda N, Huc R, Granier A, Dreyer E (2006) Temperate forest trees and stands under severe drought: a review of ecophysiological responses, adaptation processes and long-term consequences. Annals of Forest Science, 63, 625-644. 
Breeze E, Harrison E, McHattie S, et al (2011) High-resolution temporal profiling of transcripts during Arabidopsis leaf senescence reveals a distinct chronology of processes and regulation. The Plant Cell, 23, 873-894.

Campoy JA, Ruiz D, Egea J (2011) Dormancy in temperate fruit trees in a global warming context: A review. Scientia Horticulturae, 130, 357-372.

Chapin FS, Kedrowski RA (1983) Seasonal-changes in nitrogen and phosphorus fractions and autumn retranslocation in evergreen and deciduous taiga trees. Ecology, 64, 376-391.

Charles-Edwards DA, Stutzel H, Ferraris R, Beech DF (1987) An analysis of spatial variation in the nitrogen-content of leaves from different horizons within a canopy. Annals of Botany, 60, 421-426.

Chen WQ, Provart NJ, Glazebrook J, et al (2002) Expression profile matrix of Arabidopsis transcription factor genes suggests their putative functions in response to environmental stresses. The Plant Cell, 14, 559-574.

Chung H, Muraoka H, Nakamura M, Han S, Muller O, Son Y (2013) Experimental warming studies on tree species and forest ecosystems: a literature review. Journal of Plant Research, 126, 447-460.

Clausen S, Apel K (1991) Seasonal-changes in the concentration of the major storage protein and its messenger-rna in xylem ray cells of poplar trees. Plant Molecular Biology, 17, 669-678.

Cooke JEK, Weih M (2005) Nitrogen storage and seasonal nitrogen cycling in Populus: bridging molecular physiology and ecophysiology. New Phytologist, 167, 19-30.

Cooke JEK, Eriksson ME, Junttila O (2012) The dynamic nature of bud dormancy in trees: environmental control and molecular mechanisms. Plant Cell and Environment, 35, 1707-1728.

Cufar K, De Luis M, Saz MA, Crepinsek Z, Kajfez-Bogataj L (2012) Temporal shifts in leaf phenology of beech (Fagus sylvatica) depend on elevation. Trees-Structure and Function, 26, 10911100 .

del Arco JM, Escudero A, Garrido MV (1991) Effects of site characteristics on nitrogen retranslocation from senescing leaves. Ecology, 72, 701-708.

Delpierre N, Dufrene E, Soudani K, Ulrich E, Cecchini S, Boe J, Francois C (2009) Modelling interannual and spatial variability of leaf senescence for three deciduous tree species in France. Agricultural and Forest Meteorology, 149, 938-948.

Doi H, Takahashi M (2008) Latitudinal patterns in the phenological responses of leaf colouring and leaf fall to climate change in Japan. Global Ecology and Biogeography, 17, 556-561.

Dougherty PM, Hennessey TC, Zarnoch SJ, Stenberg PT, Holeman RT, Wittwer RF (1995) Effects of stand development and weather on monthly leaf biomass dynamics of a loblolly-pine (Pinus taeda $\mathrm{L}$ ) stand. Forest Ecology and Management, 72, 213-227.

Dragoni D, Schmid HP, Wayson CA, Potter H, Grimmond CSB, Randolph JC (2011) Evidence of increased net ecosystem productivity associated with a longer vegetated season in a deciduous forest in south-central Indiana, USA. Global Change Biology, 17, 886-897.

Dragoni D, Rahman AF (2012) Trends in fall phenology across the deciduous forests of the Eastern USA. Agricultural and Forest Meteorology, 157, 96-105. 
Druart N, Johansson A, Baba K, et al (2007) Environmental and hormonal regulation of the activitydormancy cycle in the cambial meristem involves stage-specific modulation of transcriptional and metabolic networks. Plant Journal, 50, 557-573.

El Zein R, Breda N, Gerant D, Zeller B, Maillard P (2011) Nitrogen sources for current-year shoot growth in 50-year-old sessile oak trees: an in situ N-15 labeling approach. Tree Physiology, 31, 13901400 .

Escudero A, Delarco JM (1987) Ecological significance of the phenology of leaf abscission. Oikos, 49, $11-14$.

Estrella N, Menzel A (2006) Responses of leaf colouring in four deciduous tree species to climate and weather in Germany. Climate Research, 32, 253-267.

Evans JR, Seemann JR (1989) The allocation of protein nitrogen in the photosynthetic apparatus: costs, consequences, and control. In:Photosynthesis (ed Briggs WR), pp. 183-205. Liss, New York.

Feller U, Fischer A (1994) Nitrogen-metabolism in senescing leaves. Critical Reviews in Plant Sciences, 13, 241-273.

Fischer AM (2007) Nutrient remobilization during leaf senescence. In:Annual Plant Reviews Volume 26: Senescence Processes in Plants (ed Gan S), pp. 87-107. Blackwell Publishing Ltd, Oxford.

Fracheboud Y, Luquez V, Bjorken L, Sjodin A, Tuominen H, Jansson S (2009) The control of autumn senescence in european aspen. Plant Physiology, 149, 1982-1991.

Friedman JM, Roelle JE, Cade BS (2011) Genetic and environmental influences on leaf phenology and cold hardiness of native and introduced riparian trees. International Journal of Biometeorology, 55, 775-787.

Fu YSH, Campioli M, Vitasse Y et al. (2014) Variation in leaf flushing date influences autumnal senescence and next year's flushing date in two temperate tree species. Proceedings of the National Academy of Sciences of the United States of America, 111, 7355-7360.

Gallardo JF, Martin A, Moreno G (1999) Nutrient efficiency and resorption in Quercus pyrenaica oak coppices under different rainfall regimes of the Sierra de Gata mountains (central western Spain). Annals of Forest Science, 56, 321-331.

Gonzalez E (2012) Seasonal patterns of litterfall in the floodplain forest of a large Mediterranean river. Limnetica, 31, 173-185.

Gordo O, Sanz JJ (2009) Long-term temporal changes of plant phenology in the Western Mediterranean. Global Change Biology, 15, 1930-1948.

Gordo O, Sanz JJ (2010) Impact of climate change on plant phenology in Mediterranean ecosystems. Global Change Biology, 16, 1082-1106.

Gunderson CA, Edwards NT, Walker AV, O'Hara KH, Campion CM, Hanson PJ (2012) Forest phenology and a warmer climate - growing season extension in relation to climatic provenance. Global Change Biology, 18, 2008-2025.

Guo YF (2013) Towards systems biological understanding of leaf senescence. Plant Molecular Biology, 82, 519-528. 
Günthardt-Goerg MS, Vollenweider P (2007) Linking stress with macroscopic and microscopic leaf response in trees: New diagnostic perspectives. Environmental Pollution, 147, 467-488.

Günthardt-Goerg MS, Kuster TM, Arend M, Vollenweider P (2013) Foliage response of young central European oaks to air warming, drought and soil type. Plant Biology, 15, 185-197.

Heide OM, Prestrud AK (2005) Low temperature, but not photoperiod, controls growth cessation and dormancy induction and release in apple and pear. Tree Physiology, 25, 109-114.

Heide OM (2011) Temperature rather than photoperiod controls growth cessation and dormancy in Sorbus species. Journal of Experimental Botany, 62, 5397-5404.

Hennessey TC, Dougherty PM, Cregg BM, Wittwer RF (1992) Annual variation in needle fall of a loblolly-pine stand in relation to climate and stand density. Forest Ecology and Management, 51, 329338.

Hikosaka K (2003) A model of dynamics of leaves and nitrogen in a plant canopy: an integration of canopy photosynthesis, leaf life span, and nitrogen use efficiency. American Naturalist, 162, 149-164.

Hortensteiner S (2006) Chlorophyll degradation during senescence. Annual Review of Plant Biology, 57, 55-77.

Hwang T, Band LE, Miniat CF, Song C, Bolstad PV, Vose JM, Love JP (2014) Divergent phenological response to hydroclimate variability in forested mountain watersheds. Global Change Biology, n/a.

Ibanez I, Primack RB, Miller-Rushing AJ, et al (2010) Forecasting phenology under global warming. Philosophical Transactions of the Royal Society B-Biological Sciences, 365, 3247-3260.

Inada N, Sakai A, Kuroiwa H, Kuroiwa T (1998) Three-dimensional analysis of the senescence program in rice (Oryza sativa L.) coleoptiles - Investigations by fluorescence microscopy and electron microscopy. Planta, 206, 585-597.

Ingvarsson PK, Garcia MV, Hall D, Luquez V, Jansson S (2006) Clinal variation in phyB2, a candidate gene for day-length-induced growth cessation and bud set, across a latitudinal gradient in European aspen (Populus tremula). Genetics, 172, 1845-1853.

IPCC (2013) Climate change 2013: the physical science basis. Contribution of working group I to the fifth assessment report of the intergovernmental panel on climate change. Cambridge University Press, Cambridge, United Kingdom and New York, NY, USA, 1535 pp.

Jeong SJ, Ho CH, Gim HJ, Brown ME (2011) Phenology shifts at start vs. end of growing season in temperate vegetation over the Northern Hemisphere for the period 1982-2008. Global Change Biology, 17, 2385-2399.

Jones MH, Bay C, Nordenhall U (1997) Effects of experimental warming on arctic willows (Salix spp.): A comparison of responses from the Canadian High Arctic, Alaskan Arctic, and Swedish Subarctic. Global Change Biology, 3, 55-60.

Jordan MO, Wendler R, Millard P (2012) Autumnal N storage determines the spring growth, N uptake and $\mathrm{N}$ internal cycling of young peach trees. Trees-Structure and Function, 26, 393-404.

Juknys R, Sujetoviene G, Zeimavicius K, Sveikauskaite I (2012) Comparison of climate warming induced changes in silver birch (Betula pendula Roth) and lime (Tilia cordata Mill.) phenology. Baltic Forestry, 18, 25-32. 
Juvany M, Muller M, Munne-Bosch S (2013) Photo-oxidative stress in emerging and senescing leaves: a mirror image? Journal of Experimental Botany, 64, 3087-3098.

Kasurinen A, Biasi C, HolopainenT, Rousi M, Maenpaa M, Oksanen E (2012) Interactive effects of elevated ozone and temperature on carbon allocation of silver birch (Betula pendula) genotypes in an open-air field exposure. Tree Physiology, 32, 737-751.

Keech O, Pesquet E, Ahad A, et al (2007) The different fates of mitochondria and chloroplasts during dark-induced senescence in Arabidopsis leaves. Plant Cell and Environment, 30, 1523-1534.

Keeling CD, Chin JFS, Whorf TP (1996) Increased activity of northern vegetation inferred from atmospheric $\mathrm{CO}_{2}$ measurements. Nature, 382, 146-149.

Keskitalo J, Bergquist G, Gardestrom P, Jansson S (2005) A cellular timetable of autumn senescence. Plant Physiology, 139, 1635-1648.

Killingbeck KT, Costigan SA (1988) Element resorption in a guild of understory shrub species: niche differentiation and resorption thresholds. Oikos, 53, 366-374.

Killingbeck KT (1996) Nutrients in senesced leaves: Keys to the search for potential resorption and resorption proficiency. Ecology, 77, 1716-1727.

Killingbeck KT (2004) Nutrient resorption. In: Plant cell death processes (ed Noodén LD), pp. 215226. Elsevier Academic Press

Lebourgeois F, Pierrat JC, Perez V, Piedallu C, Cecchini S, Ulrich E (2010) Simulating phenological shifts in French temperate forests under two climatic change scenarios and four driving global circulation models. International Journal of Biometeorology, 54, 563-581.

Leuzinger S, Zotz G, Asshoff R, Korner C (2005) Responses of deciduous forest trees to severe drought in Central Europe. Tree Physiology, 25, 641-650.

Lim PO, Woo HR, Nam HG (2003) Molecular genetics of leaf senescence in Arabidopsis. Trends in Plant Science, 8, 272-278.

Marchin R, Zeng HN, Hoffmann W (2010) Drought-deciduous behavior reduces nutrient losses from temperate deciduous trees under severe drought. Oecologia, 163, 845-854.Matsumoto K (2010) Causal factors for spatial variation in long-term phenological trends in Ginkgo biloba L. in Japan.

International Journal of Climatology, 30, 1280-1288.

Matsumoto K, Ohta T, Irasawa M, Nakamura T (2003) Climate change and extension of the Ginkgo biloba L. growing season in Japan. Global Change Biology, 9, 1634-1642.

Matzek V, Vitousek PM (2009) N : P stoichiometry and protein : RNA ratios in vascular plants: an evaluation of the growth-rate hypothesis. Ecology Letters, 12, 765-771.

Menzel A, Fabian P (1999) Growing season extended in Europe. Nature, 397, 659.

Menzel A, Sparks TH, Estrella N, et al (2006) European phenological response to climate change matches the warming pattern. Global Change Biology, 12, 1969-1976.

Migita C, Chiba Y, Tange T (2007) Seasonal and spatial variations in leaf nitrogen content and resorption in a Quercus serrata canopy. Tree Physiology, 27, 63-70. 
Milla R, Castro-Diez P, Maestro-Martinez M, Montserrat-Marti G (2005) Environmental constraints on phenology and internal nutrient cycling in the Mediterranean winter-deciduous shrub Amelanchier ovalis Medicus. Plant Biology, 7, 182-189.

Millard P, Sommerkorn M, Grelet GA (2007) Environmental change and carbon limitation in trees: a biochemical, ecophysiological and ecosystem appraisal. New Phytologist, 175, 11-28.

Montserrat-Marti G, Camarero JJ, Palacio S, Perez-Rontome C, Milla R, Albuixech J, Maestro M (2009) Summer-drought constrains the phenology and growth of two coexisting Mediterranean oaks with contrasting leaf habit: implications for their persistence and reproduction. Trees-Structure and Function, 23, 787-799.

Morin X, Lechowicz MJ, Augspurger C, O' Keefe J, Viner D, Chuine I (2009) Leaf phenology in 22 North American tree species during the 21st century. Global Change Biology, 15, 961-975.

Morin X, Roy J, Sonie L, Chuine I (2010) Changes in leaf phenology of three European oak species in response to experimental climate change. New Phytologist, 186, 900-910.

Mostowska A (2005) Leaf senescence and photosynthesis. In:Handbook of Photosynthesis (ed Pessarakli M), pp. 691-716. CRC Press, Taylor \& Francis Group, Boca Raton.

Munne-Bosch S, Jubany-Mari T, Alegre L (2001) Drought-induced senescence is characterized by a loss of antioxidant defences in chloroplasts. Plant Cell and Environment, 24, 1319-1327.

Munne-Bosch S, Alegre L (2004) Die and let live: leaf senescence contributes to plant survival under drought stress. Functional Plant Biology, 31, 203-216.

Murphy PG, Lugo AE (1986) Ecology of tropical dry forest. Annual Review of Ecology and Systematics, 17, 67-88.

Nakamura M, Muller O, Tayanagi S, Nakaji T, Hiura T (2010) Experimental branch warming alters tall tree leaf phenology and acorn production. Agricultural and Forest Meteorology, 150, 1026-1029.

Neilsen D, Millard P, Neilsen GH, Hogue EJ (1997) Sources of N for leaf growth in a high-density apple (Malus domestica) orchard irrigated with ammonium nitrate solution. Tree Physiology, 17, 733739.

Niederholzer FJA, Dejong TM, Saenz JL, Muraoka TT, Weinbaum SA (2001) Effectiveness of fall versus spring soil fertilization of field-grown peach trees. Journal of the American Society for Horticultural Science, 126, 644-648.

Niinemets U, Tamm U (2005) Species differences in timing of leaf fall and foliage chemistry modify nutrient resorption efficiency in deciduous temperate forest stands. Tree Physiology, 25, 1001-1014.

Norby RJ, Hartz-Rubin JS, Verbrugge MJ (2003) Phenological responses in maple to experimental atmospheric warming and $\mathrm{CO}_{2}$ enrichment. Global Change Biology, 9, 1792-1801.

Onoda Y, Hikosaka K, Hirose T (2004) Allocation of nitrogen to cell walls decreases photosynthetic nitrogen-use efficiency. Functional Ecology, 18, 419-425.

Pedersen LB, Bille-Hansen J (1999) A comparison of litterfall and element fluxes in even aged Norway spruce, sitka spruce and beech stands in Denmark. Forest Ecology and Management, 114, 5570. 
Paakkonen E, Gunthardt-Goerg MS, HolopainenT. (1998) Responses of leaf processes in a sensitive birch (Betula pendula Roth) clone to ozone combined with drought. Annals of Botany, 82, 49-59.

Peng ZP, Li CJ (2005) Transport and partitioning of phosphorus in wheat as affected by P withdrawal during flag-leaf expansion. Plant and Soil, 268, 1-11.

Penuelas J, Filella I (2001) Phenology - Responses to a warming world. Science, 294, 793-+.

Penuelas J, Filella I, Comas P (2002) Changed plant and animal life cycles from 1952 to 2000 in the Mediterranean region. Global Change Biology, 8, 531-544.

Petterle A, Karlberg A, Bhalerao RP (2013) Daylength mediated control of seasonal growth patterns in perennial trees. Current Opinion in Plant Biology, 16, 301-306.

Pregitzer KS, Zak DR, Talhelm AF, Burton AJ, Eikenberry JR (2010) Nitrogen turnover in the leaf litter and fine roots of sugar maple. Ecology, 91, 3456-3462.

Pudas E, Leppala M, Tolvanen A, Poikolainen J, Venalainen A, Kubin E (2008) Trends in phenology of Betula pubescens across the boreal zone in Finland. International Journal of Biometeorology, 52, 251-259.

Pugnaire FI, Chapin FS (1992) Environmental and physiological factors governing nutrient resorption efficiency in barley. Oecologia, 90, 120-126.

Rennenberg H, Wildhagen H, Ehlting B (2010) Nitrogen nutrition of poplar trees. Plant Biology, 12, 275-291.

Resman L, Howe G, Jonsen D, et al (2010) Components acting downstream of short day perception regulate differential cessation of cambial activity and associated responses in early and late clones of hybrid poplar. Plant Physiology, 154, 1294-1303.

Richardson AD, Bailey AS, Denny EG, Martin CW, O'Keefe J (2006) Phenology of a northern hardwood forest canopy. Global Change Biology, 12, 1174-1188.

Rohde A, Bhalerao RP (2007) Plant dormancy in the perennial context. Trends in Plant Science, 12, 217-223.

Ruuhola T, Leppanen T, Lehto T (2011) Retranslocation of nutrients in relation to boron availability during leaf senescence of Betula pendula Roth. Plant and Soil, 344, 227-240.

Sanchez CA (2006) Phosphorus. In:Handbook of Plant Nutrition (eds Barker AV, Pilbeam DJ), pp. 5190. CRC Press.

Schreiber SG, Ding C, Hamann A, Hacke UG, Thomas BR, Brouard JS (2013) Frost hardiness vs. growth performance in trembling aspen: an experimental test of assisted migration. Journal of Applied Ecology, 50, 939-949.

Silla F, Escudero A (2004) Nitrogen-use efficiency: trade-offs between N productivity and mean residence time at organ, plant and population levels. Functional Ecology, 18, 511-521.

Silla F, Escudero A (2006) Coupling N cycling and N productivity in relation to seasonal stress in Quercus pyrenaica Willd. saplings. Plant and Soil, 282, 301-311.

Silla F, Fleury M, Mediavilla S, Escudero A (2008) Effects of simulated herbivory on photosynthesis and N resorption efficiency in Quercus pyrenaica Willd. saplings. Trees-Structure and Function, 22, 785-793. 
Soolanayakanahally RY, Guy RD, Silim SN, Song MH (2013) Timing of photoperiodic competency causes phenological mismatch in balsam poplar (Populus balsamifera L.). Plant Cell and

Environment, 36, 116-127.

Staaf H, Stjernquist I (1986) Seasonal dynamics, especially autumnal retranslocation, of nitrogen and phosphorus in foliage of dominant and suppressed trees of beech, Fagus sylvatica. Scandinavian Journal of Forest Research, 1, 333-342.

Staelens J, Nachtergale L, De Schrijver A, Vanhellemont M, Wuyts K, Verheyen K (2011) Spatiotemporal litterfall dynamics in a 60 -year-old mixed deciduous forest. Annals of Forest Science, 68, 8998 .

Stockli R, Vidale PL (2004) European plant phenology and climate as seen in a 20-year AVHRR landsurface parameter dataset. International Journal of Remote Sensing, 25, 3303-3330.

Tanino K, Kalcsits L, Silim S, Kendall E, Gray GR (2010) Temperature-driven plasticity in growth cessation and dormancy development in deciduous woody plants: a working hypothesis suggesting how molecular and cellular function is affected by temperature during dormancy induction. Plant Mol Biol, 73, 49-65.

Ueda MU, Mizumachi E, Tokuchi N (2009) Allocation of nitrogen within the crown during leaf expansion in Quercus serrata saplings. Tree Physiology, 29, 913-919.

Vergutz L, Manzoni S, Porporato A, Novais RF, Jackson RB (2012) Global resorption efficiencies and concentrations of carbon and nutrients in leaves of terrestrial plants. Ecological Monographs, 82, 205220 .

Vitasse Y, Porte AJ, Kremer A, Michalet R, Delzon S (2009) Responses of canopy duration to temperature changes in four temperate tree species: relative contributions of spring and autumn leaf phenology. Oecologia, 161, 187-198.

Vitasse Y, Bresson CC, Kremer A, Michalet R, Delzon S (2010) Quantifying phenological plasticity to temperature in two temperate tree species. Functional Ecology, 24, 1211-1218.

Vitasse Y, Francois C, Delpierre N, Dufrene E, Kremer A, Chuine I, Delzon S (2011) Assessing the effects of climate change on the phenology of European temperate trees. Agricultural and Forest Meteorology, 151, 969-980.

Waddell KJ, Fox CW, White KD, Mousseau TA (2001) Leaf abscission phenology of a scrub oak: consequences for growth and survivorship of a leaf mining beetle. Oecologia, 127, 251-258.

Warren JM, Norby RJ, Wullschleger SD (2011) Elevated $\mathrm{CO}_{2}$ enhances leaf senescence during extreme drought in a temperate forest. Tree Physiology, 31, 117-130.

Wendler R, Millard P (1996) Impacts of water and nitrogen supplies on the physiology, leaf demography and nitrogen dynamics of Betula pendula. Tree Physiology, 16, 153-159.

Wibbe ML, Blanke MM, Lenz F (1994) Respiration of apple-trees between leaf fall and leaf emergence. Environmental and Experimental Botany, 34, 25-30.

Wildhagen H, Bilela S, Rennenberg H (2013) Low temperatures counteract short-day induced nitrogen storage, but not accumulation of bark storage protein transcripts in bark of grey poplar (Populus $x$ canescens) trees. Plant Biology, 15, 44-56. 
Xu ZF, Hu TX, Zhang YB (2012) Effects of experimental warming on phenology, growth and gas exchange of treeline birch (Betula utilis) saplings, Eastern Tibetan Plateau, China. European Journal of Forest Research, 131, 811-819.

Yasumura Y, Onoda Y, Hikosaka K, Hirose T (2005) Nitrogen resorption from leaves under different growth irradiance in three deciduous woody species. Plant Ecology, 178, 29-37. 


\section{Figure captions}

Fig. 1. Leaf-litter $\mathrm{N}$ concentration in a 15 -year record of a natural forest of Acer saccharum, redrawn from Pregitzer et al., (2010).

Fig 2. Location of the pool of mobile $\mathrm{N}$ throughout the annual cycle of a winter deciduous plant.

a) During the dormant period, nutrients in woody tissues can be differentiated into a mobile and an immobile pool. b) At the beginning of the active part of the annual cycle, mobile nutrients are mobilized for the synthesis of new tissues, and the woody storage is depleted. c) During the active season, newly absorbed nutrients can be diverted to tissues of the current year and, in species with continuous growth, be allocated to late new tissues. d, e) During leaf senescence, resorbed nutrients are transported to the woody tissues before leaves are shed, and unresorbed nutrients are lost with the leaf litter. In d, species showing drought-senescence may undergo premature partial leaf senescence and shed a fraction of the leaves if the summer drought is sufficiently intense. In e, the leaves reaching the autumn undergo a synchronous autumnal ontogenic leaf senescence that replenishes the woody pool of mobile nutrients with the resorbed nutrients and returns the unresorbed nutrients to the soil through the production of leaf litter.

Fig 3. The effects of a) warming and b) drought on the dynamics of leaf fall in canopies, represented as daily values $\left(\mathrm{g} \mathrm{m}^{-2} \mathrm{~d}^{-1}\right)$. In both a) and b), the black line is leaf fall under the current climate. In a), the effects of warming on leaf fall of a species sensitive to warming are represented by the orange line. A line in a) representing a species under strict control of photoperiod would not differ from the black line under current conditions, unless the speed of senescence is slowed by warming that would slightly delay senescence, as represented by the grey line. Three different effects of drought are represented in b): drought elicits a premature peak of leaf fall (red and blue lines) that occurs weeks before the autumnal fall (red line) or is delayed and is poorly differentiated from the autumnal fall (blue line), or the premature peak does not occur and there is and advancement of the dates of the autumnal fall 
(green line). A case mixing a premature leaf fall peak and advanced autumnal fall is not represented in b), but we cannot discard its occurrence in nature. 


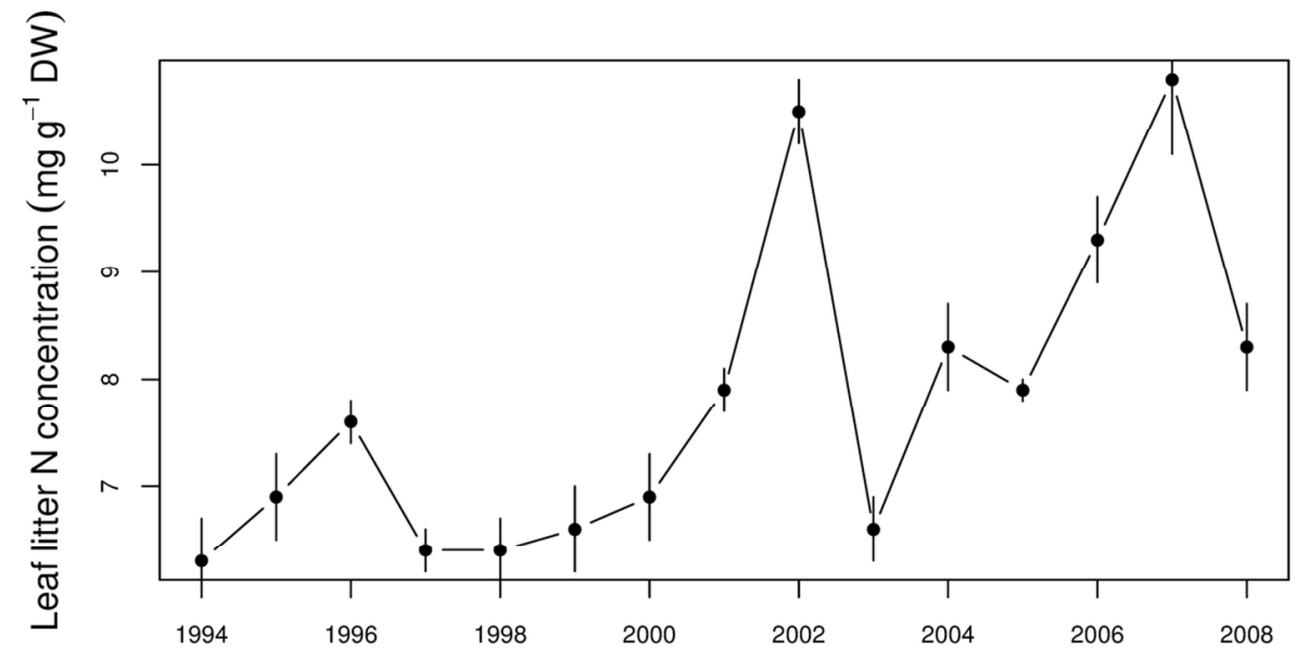

$101 \times 54 \mathrm{~mm}(300 \times 300 \mathrm{DPI})$ 


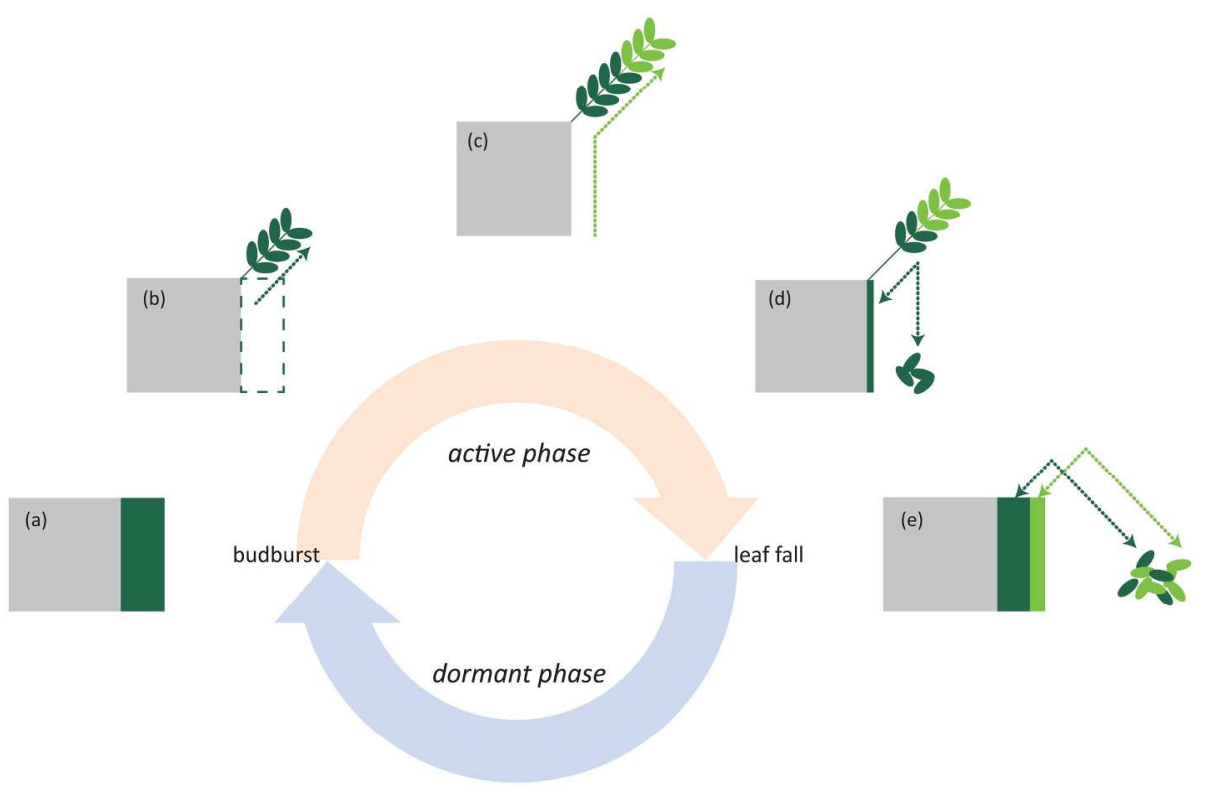

$214 \times 148 \mathrm{~mm}(300 \times 300$ DPI $)$ 


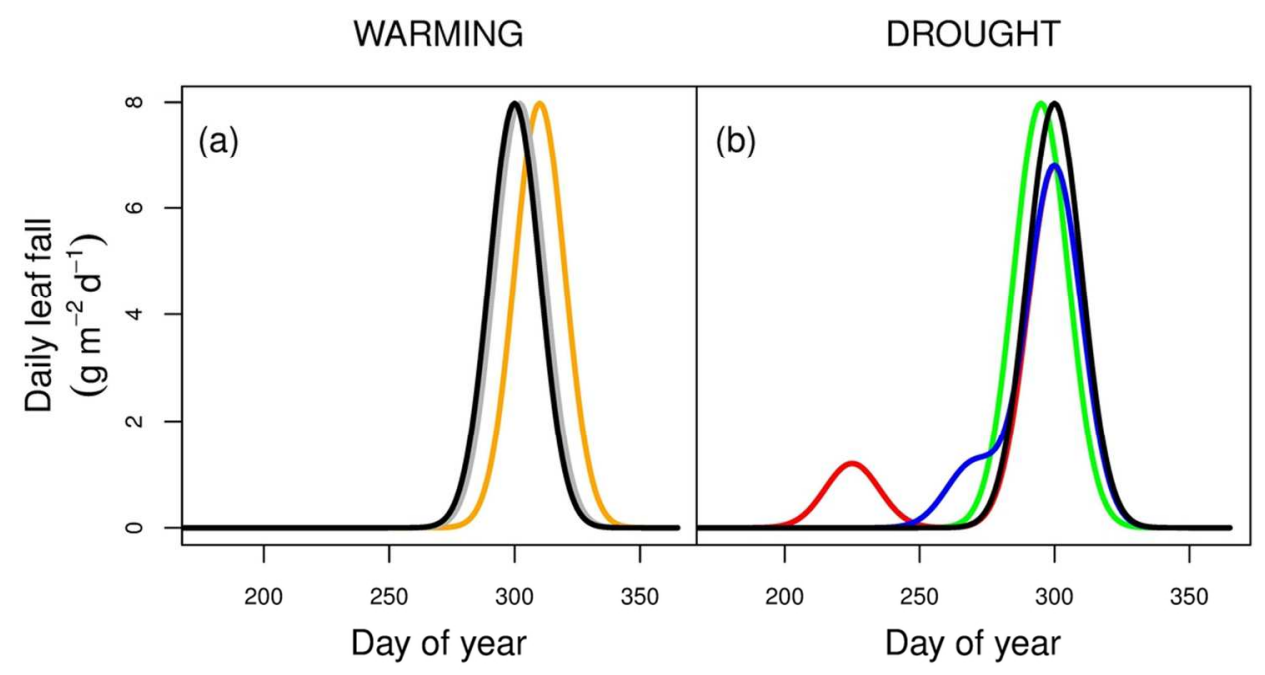

$105 \times 56 \mathrm{~mm}(300 \times 300 \mathrm{DPI})$ 